\title{
CONSIDERACIONES SOBRE LA HISTORIA DE LA PRIORIDAD TAXONÓMICA DE ONCIDIUM ORNITHORHYNCHUM
}

\author{
Laura C. Mazo $^{1}$, Alberto Gómez-Gutiérrez ${ }^{1,2,5}$, Sonia R. Quintanilla ${ }^{1,2}$, \\ Jaime E. Bernal ${ }^{1,2}$ \& Pedro Ortiz-Valdivieso, S.J. $\uparrow^{2,3}$ \\ ${ }^{1}$ Instituto de Genética Humana, Facultad de Medicina, Pontificia Universidad Javeriana, \\ Cra 7 \# 40-62, edificio 32, Bogotá D.C., 110231, Colombia \\ ${ }^{2}$ Iniciativa Genómica Javeriana, Pontificia Universidad Javeriana, Cra 7 \# 40-62, edificio 32, \\ Bogotá D. C., 110231, Colombia \\ ${ }^{3}$ Asociación Bogotana de Orquideología, Avenida calle 63 \# 68G-14, Bogotá D. C., Colombia \\ ${ }^{5}$ Autor para correspondencia: agomez@javeriana.edu.co \\ $\dagger$ Pedro Ortiz-Valdivieso, S.J. (1926-2012)
}

\begin{abstract}
RESUMEN: La historia de la prioridad taxonómica de la orquídea Oncidium ornithorhynchum está aún por aclarar si se consideran las diferentes descripciones y publicaciones de esta especie propuestas en los siglos XVIII y XIX por botánicos como José Celestino Mutis, John Lindley, Alexander von Humboldt, Aimé Bonpland y Carl S. Kunth, entre otros. Con el fin de resolver las inconsistencias en los reportes taxonómicos de esta especie en el transcurso del tiempo, y teniendo como base la reciente aclaración realizada por Jiménez y Hágsater sobre la identidad del ejemplar tipo conservado en París, hemos procedido a ordenar las fuentes primarias asociadas con su descripción y nomenclatura botánica.
\end{abstract}

ABSTRACT. The history of the nomenclatural taxonomic priority of the orchid Oncidium ornithorhynchum is yet to be clarified, as successive descriptions and publications of this species were proposed in the eighteenth and nineteenth centuries by botanists such as José Celestino Mutis, John Lindley, Alexander von Humboldt, Aimé Bonpland and Carl S. Kunth, among others. In order to resolve the inconsistencies in taxonomic reports of this species in the course of time, and based on the recent clarification by Jiménez and Hágsater on the type specimen conserved in Paris, we proceeded to review the primary sources associated with its description and botanical nomenclature.

Palabras claves: Orquídeas, Oncidium ornithorhynchum, O. pyramidale, exsicados, herbario

Introducción. La familia de las orquídeas cuenta con el mayor número de especies de todo el reino vegetal aproximadamente 30000 (Montes y Eguiluz 1996). Ellas se encuentran en todos los continentes y en todos los climas, con excepción de las zonas polares. Colombia puede considerarse como una zona privilegiada para las orquídeas por la variedad de climas y zonas ecológicas de su territorio. Se han registrado hasta hoy más de 3000 especies de orquídeas en el territorio colombiano (Asociación Bogotana de Orquideología 2013).

Oncidium ornithorhynchum Kunth es una especie de orquídea perteneciente al género Oncidium Swartz (subtribu Oncidiinae) cuyo nombre deriva de la raíz griega onkos, tumor, refiriéndose al callo tuberculado del labelo. El nombre específico ornithorhynchum procede de las palabras griegas ornitho, relativo a las aves, y rhynchos que significa pico. Son plantas epífitas de los páramos, ubicadas entre 2850 y 3340 metros sobre el nivel del mar (msnm) y se reconocen por la inflorescencia erecta, en forma "piramidal" (Jiménez \& Hágsater 2010, Pridgeon et al. 2009).

La descripción taxonómica de Oncidium ornithorhynchum ha variado con el tiempo y los círculos de investigadores involucrados, hasta presentarse confusiones fenotípicas y biogeográficas como la

\footnotetext{
* Este artículo fue preparado en el marco de la celebración del 40 aniversario del Jardín Botánico Lankester.
} 
que reportaron recientemente Jiménez y Hágsater (2010). Este no es un caso único en el trabajo combinado del trío científico conformado por Humboldt, Bonpland y Kunth (H.B.K.), pues se conocen al menos 2 ejemplos más de inconsistencias biogeográficas en las colecciones H.B.K. La primera, en la que la localidad de la colección "Santa Fe" fue interpretada como "Santa Fe, México" (hoy en día parte del estado de Nuevo México, USA), lo cual no sólo le sucedió a Kunth, sino también a Linneo (Oscar Vargas, com. pers. 2012), como fue publicado respectivamente para dos especies de la familia Asteraceae, Diplostephium phylicoides (Kunth) Wedd. (Vargas 2011) y Lycoseris mexicana (L.) Cass (Díaz-Piedrahita et al. 1997)

La primera de estas inconsistencias en la colección H.B.K., fue reportada por Vargas (2011) en los siguientes términos:

"Diplostephium phylicoides (Kunth) Wedd., Chlor. And. 1: 205. 1856. Distribution: COl. SERIES: Phylicoidea. Aster phylicoides Kunth, Nov. Gen. Sp. Pl. 4:93. 1820. TYPE: COLOMBIA [erroneously cited as Mexico], [without date], Humboldt \& Bonpland s.n. (P "Herb. Bonpland", holotype; P "Herb. Bonpland", isotype; $\mathrm{F}$, fragment). The type specimen was supposed to be collected in Mexico, it is known that some of the Humboldt \& Bonpland collections were wrongly labeled as collected in Santa Fe, Mexico (now USA), while they [were collected near] Bogotá (before: Santa Fe de Bogotá), Colombia”.

La segunda inconsistencia biogeográfica en la colección H.B.K., correspondiente a la orquídea Telipogon nervosus Druce, fue reportada por el padre Pedro Ortiz-Valdivieso, en los siguientes términos:

"Una de las primeras plantas que envió Mutis a Linneo fue recolectada en las minas de oro de Suratá (Santander) que Linneo interpretó de manera equivocada y publicó como Tradescantia nervosa Linn. en 1771. Mutis, en cambio, sí se dio cuenta de que se trataba de lo que Linneo llamaba una ginandra (hoy orquídea) y pensó en darle el nombre de Mormolycanthus tradescantioides pero nunca la publicó el gaditano y esto lo conocemos solo por una carta de Mutis al botánico sueco Peter Jonas Bergius (1730-1790) con fecha de enero de 1786 (Archivo epistolar del sabio naturalista Don José Celestino Mutis 1968, pp. 277-292). Humboldt y Bonpland encontraron la misma planta, probablemente en los alrededores de Bogotá (donde todavía es frecuente), y no, como se afirma en Nova genera, donde se anota que crece "sobre los árboles en la regiones templadas del Reino neogranadino, junto a Santa Ana y Mariquita, alt. 400 toesas" (lámina LXXV del Nova genera et species plantarum). Esta especie nunca ha sido encontrada de nuevo en esa región y a alturas tan bajas (600 m sobre el nivel del mar), y de ordinario se ha encontrado entre los matorrales en el suelo. Probablemente hubo alguna confusión en las fichas. Pero lo que sí estuvo correcto fue el publicarla como un nuevo género Telipogon angustifolius Kunth solo que, como ya había sido publicada por Linneo con un epíteto específico propio, era necesario conservarlo, y así, en 1917, el botánico británico George Claridge Druce (1850-1932) hizo la nueva combinación a Telipogon nervosus, nombre que es actualmente aceptado". (Ortiz-Valdivieso \& Gómez, en imprenta).

Con base en estos antecedentes, y en las consideraciones particulares expuestas en lo que concierne a la orquídea Oncidium ornithorhynchum, es conveniente ordenar la cronología de las diferentes descripciones taxonómicas de esta especie para resolver adecuadamente su identidad.

Cronología de la descripción de Oncidium ornithorhynchum. Esta especie fue colectada y registrada por primera vez por José Celestino Mutis (1732-1808) en la Real Expedición Botánica del Nuevo Reino de Granada que funcionó formalmente entre los años 1783 y 1816. En su descripción, Mutis no registró su nombre taxonómico en la lámina correspondiente, y ésta sería denominada posteriormente por los estudiosos del Real Jardín Botánico de Madrid, como Oncidium pyramidale Lindl refiriendo que el epíteto específico proviene del término latino pyramis, -idis = pirámide, en clara alusión a la forma de la inflorescencia de esta especie (Traducido del latín por Pedro Ortiz Valdivieso, S.J., 2000, p. 51).

En medio de los reportes botánicos de la Real Expedición Botánica del Nuevo Reino de Granada, y considerando que José Celestino Mutis llegó a este virreinato español en 1760 , se puede considerar que 

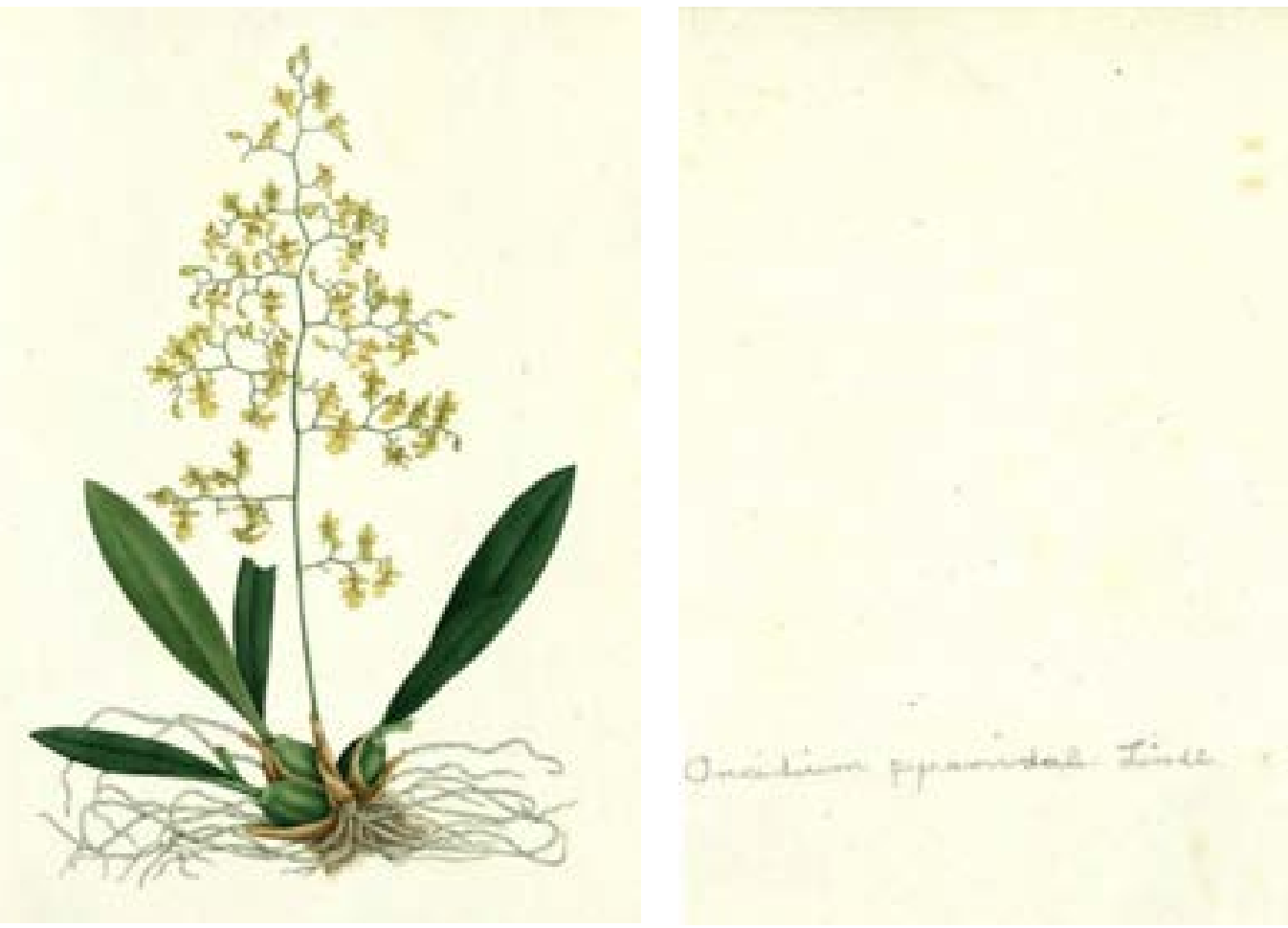

FiguRA 1. A - Lámina original a color de la orquídea Oncidium pyramidale en la colección de la Flora de la Real Expedición Botánica del Nuevo Reino de Granada. Esta aparece sin descriptor taxonómico. B - En el verso de la lámina original aparece efectivamente la inscripción "Oncidium pyramidale Lindl." manuscrita a lápiz en la parte inferior izquierda, y esta descripción fue atribuida a Charles Schweinfurth (1890-1970). Otras inscripciones reportadas sobre esta lámina original son: "537" [tachado]. Inscripción manuscrita a lápiz [s. XX], en la parte inferior derecha y "8.200" en el verso, inscripción manuscrita a lápiz, en la parte superior derecha. DIV. III A-486, en el Real Jardín Botánico de Madrid (http://www.rjb.csic.es/icones/mutis/paginas/laminadibujo.php?lamina=837).

el reporte no fechado de esta orquídea habría tenido lugar entre 1760 y 1808 , año de su fallecimiento. Esta especie, dibujada por uno de los pintores de la Expedición Botánica en aquella época (Fig.1), fue descrita en el siglo XX por el Padre Pedro Ortiz Valdivieso, S.J. (1926-2012) como:

"Planta epifita de tamaño mediano, con pseudobulbos agregados ovoides, $2.5-7 \mathrm{~cm}$ de alto, cubiertos en la base por 2 o 3 pares de vainas conduplicadas, escamosas, con ápice agudo, bi-trifoliadas; tiene hojas elíptica-oblongas hasta oblanceoladas, agudas o corto-acuminadas, de $14-20 \mathrm{~cm}$ de largo y 3,38 $\mathrm{cm}$ de ancho. Se caracteriza por presentar una inflorescencia que nace de la axila de una vaina basal y es paniculada, multiflora, suberecta, de forma generalmente piramidal, de hasta $70 \mathrm{~cm}$ de largo, incluyendo el escapo, flores pequeñas, amarillas con manchas pardas, fragantes, con segmentos extendidos; sépalo dorsal oblongo-lanceolado, ca. $7.5 \mathrm{~mm}$ de ancho, laterales libres, linear-lanceolados, oblicuos ligeramente más largos que el dorsal, pétalos aovado-oblongos, abruptamente agudos, apiculados, de igual longitud sépalo dorsal pero el doble de ancho; labelo más largo que los otros segmentos, pandurado-trilobado, sésil, con base abrupto-auriculada, bilobado en el ápice, 10-12 mm de largo y $9.8-11.3 \mathrm{~mm}$ de ancho a través de los lóbulos laterales; los lóbulos laterales suborbiculares, lóbulo medio oborado, emarginado o bilobado; disco en la base, con un callo plurituberculado, blanco, columna pequeña, fuertemente signoidea en vista lateral ca. $3 \mathrm{~mm}$ de alto, con un par de aletas erectas en la pared apical, profundamente bilobuladas, tabla infra estigmática prominente; róstelo linear, antera 


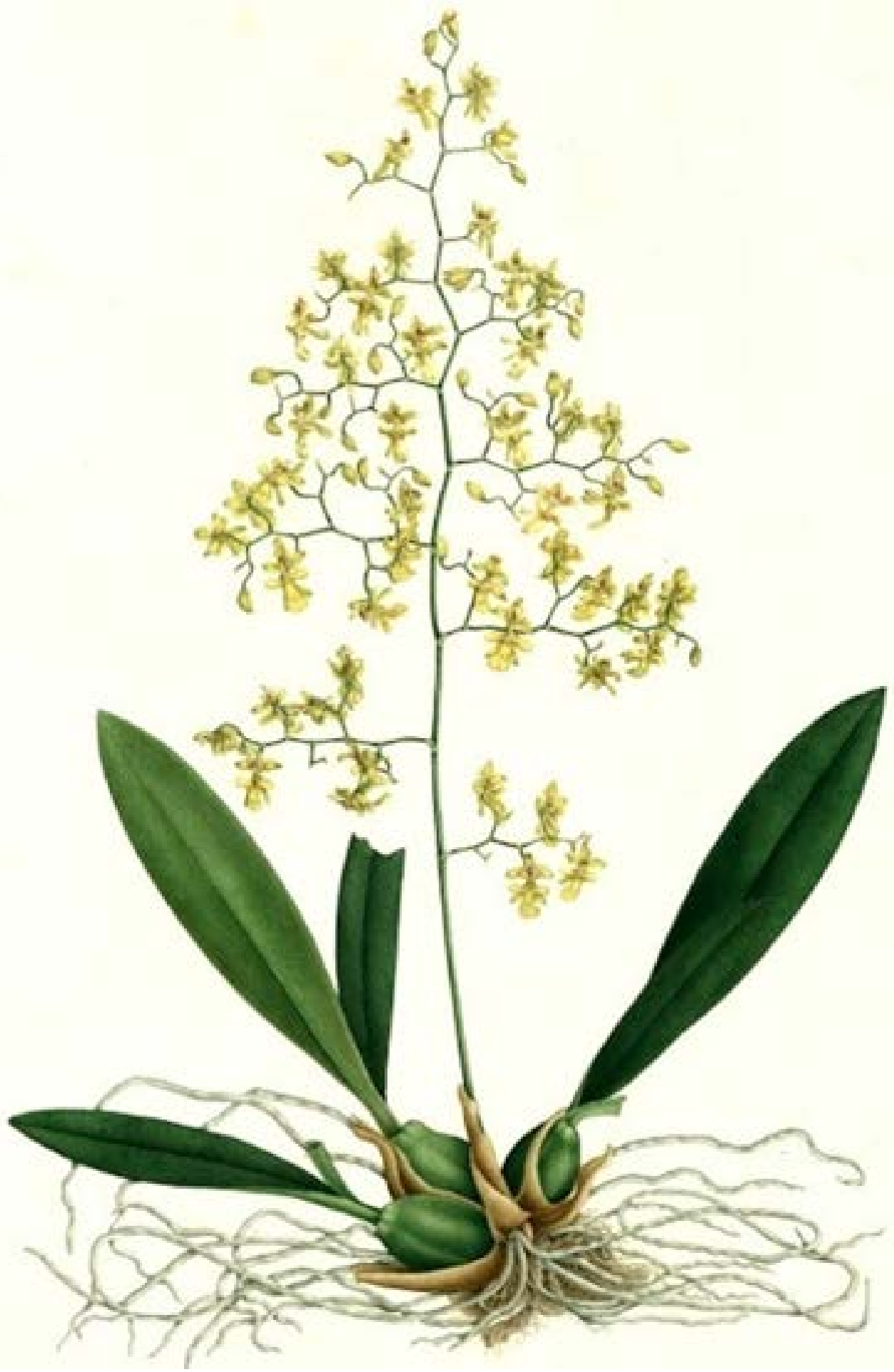

Figura 2. Lámina 39 que acompaña la publicación impresa de la orquídea Oncidium pyramidale en la obra Flora de la Real Expedición Botánica del Nuevo Reino de Granada. Vol. XI, Orchideaceae, Vol XI. Tomo 5. 

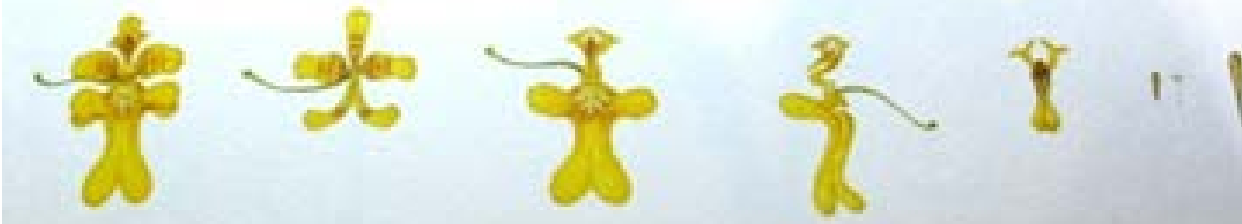

FIgURA 3. Lámina no. 486a que acompaña la publicación original de Oncidium pyramidale en la obra Flora de la Real Expedición Botánica del Nuevo Reino de Granada. Vol. XI, Orchideaceae, Vol XI. Tomo 5.

alargada, polinios en número de 2 con estípite largo y viscidio pequeño (Figs. 2-3). Su hábitat y distribución es en diversas zonas montañosas de Colombia, en clima frio; aunque también ha sido herborizada en Ecuador y Perú" (Traducido del latín por Pedro Ortiz Valdivieso, S.J. 2000)

Por otro lado, a comienzos del siglo XIX, Alexander von Humboldt (1769-1859) y Aimé Bonpland (17731858) viajaron a América y colectaron varias especies de orquídeas, que fueron enviadas al herbario del Museo Nacional de Historia Natural de París (Fig. 4). Posteriormente, en el año 1815, basándose en el ejemplar tipo colectado por Humboldt y Bonpland, Carl Sigismund Kunth (1788-1855) publica la descripción de Oncidium ornithorhynchum (Fig. 5) en el tomo I de la obra Nova Genera et Species Plantarum (Fig. 6), sin referirse al color de la especie colectada. Esta especie habría sido publicada coloreada en amarillo sin autorización de los colectores en una de las ediciones de lujo del Nova Genera et Species Plantarum. En efecto, Jiménez y Hágsater (2010) refieren que más adelante, en el curso del siglo XIX, George Ure Skinner (1804-1867) habría enviado a James Bateman (1811-1897) una orquídea colectada en Guatemala, quien la publicó erróneamente en 1837 como Oncidium ornithorhynchum (Fig. 7) en su obra The Orchidaceae of México and Guatemala (Jiménez \& Hágsater 2010) (Fig. 8). En esta publicación centroamericana solo se hace referencia a Humboldt y Kunth (sic), excluyendo al botánico Aimé Bonpland, colector y coautor del Nova Genera et Species Plantarum. También mencionan Jiménez y Hágsater (2010) que hay copias coloreadas a mano donde las flores de esta especie se representaban de color amarillo; afirmando que seguramente se debía a que el dibujo se hizo a partir de un espécimen seco, dando prioridad a la referencia sobre el lugar en donde habría sido colectada la planta.
Luego, en 1840, John Lindley (1799-1865) publica incorrectamente a esta misma especie como Oncidium ornithorhynchum (Fig. 9) en el Botanical Register (Fig. 10) y la describe, haciendo en primer lugar referencia a la descripción previa de Humboldt, Bonpland y Kunth $\mathrm{y}$, en segundo lugar, a la descripción de Bateman.

En el año 1845, Sir William Jardine (1800-1874) y colaboradores describen esta orquídea por primera vez con el nombre de Oncidium pyramidale en The Annals and Magazine of Natural History (Fig. 11). Este nuevo nombre, cuya prioridad se atribuye a Lindley, obedece a que sería una especie intermedia entre Oncidium excavatum Lindl y Oncidium ornithorhynchum, y hace referencia a una colecta de Theodor Hartweg en la región de Pasto, en el sur de Colombia, sin especificar su color ni publicar la lámina correspondiente.

A mediados del siglo XIX y a comienzos del siglo $\mathrm{XX}$, se propondrían como sinónimos de esta especie a Oncidium chrysopyramis Rchb.f. \& Warsz (Fig. 12), publicada en el año 1854 por Berthold Seemann (1825-1871) y Wilhelm Seemann (c1820-1868) en Bonplandia, y a Oncidium maderoi Schltr (Fig. 13), publicada en el año 1920 por Friedrich Fedde (18731942) en Repertorium Specierum Novarum Regni Vegetabilis.

En el año 1922 Fritz Krænzlin (1847-1934) ilustró esta especie con el nombre Oncidium pyramidale Lindl. en su obra Orchidaceae-Monandrae, Tribus Oncidiinae-Odontoglosseae pars II (Fig. 14), especificando que se distribuye en Colombia y Ecuador, sin ninguna referencia a Centroamérica, ni a Oncidium ornithorhynchum.

Recientemente, en 1996, María Dolores Montes y Pedro Eguiluz, en su publicación El cerro, frontera abierta recorrido ecológico por el cerro de Usaquén reportan - con el nombre que les fue indicado por Pedro Ortiz Valdivieso - la presencia de Oncidium 


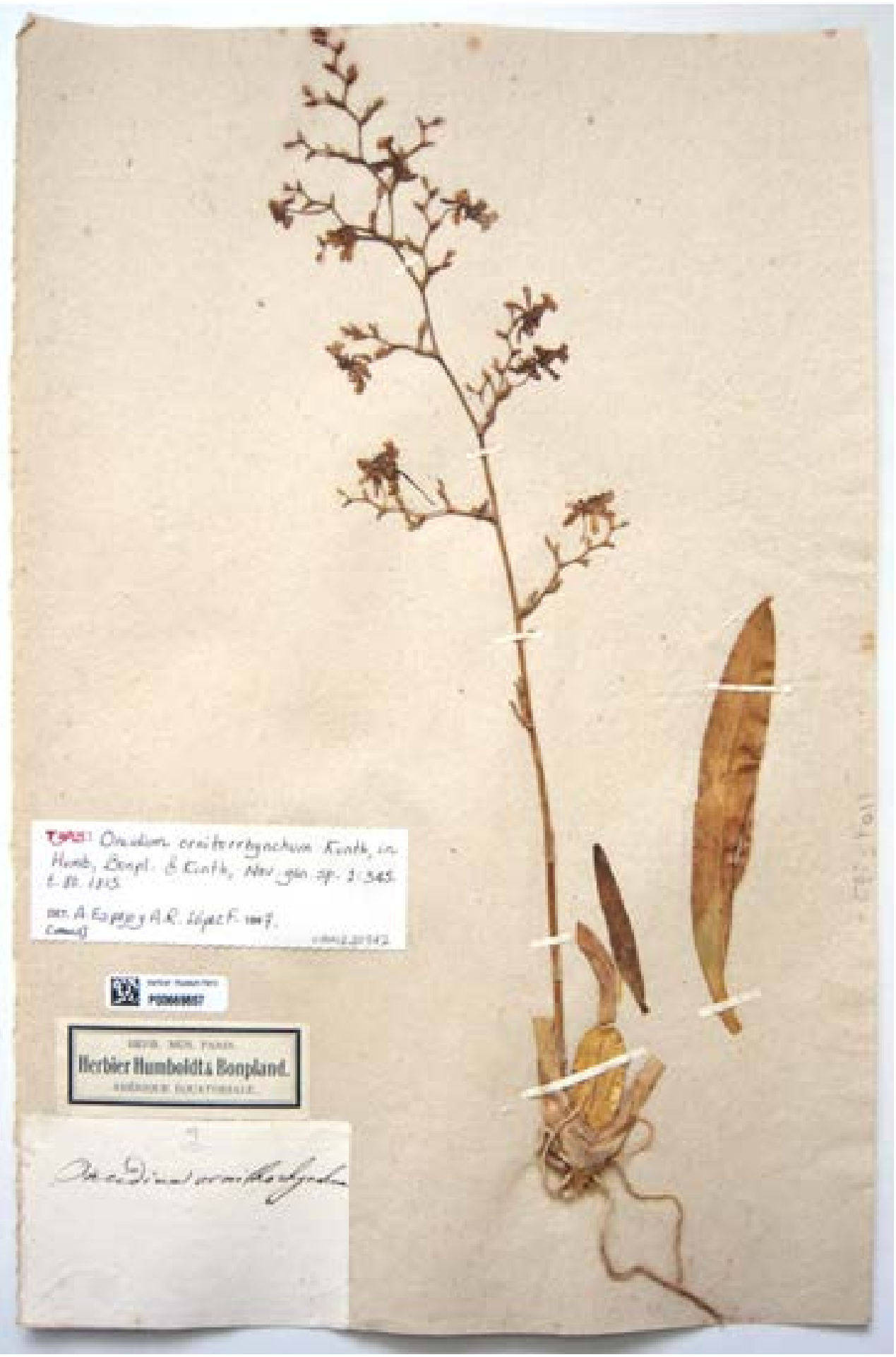

FiguRa 4. Foto del ejemplar tipo de Oncidium ornithorhynchum en el herbario de París. Tomada por Alberto Gómez Gutiérrez. 


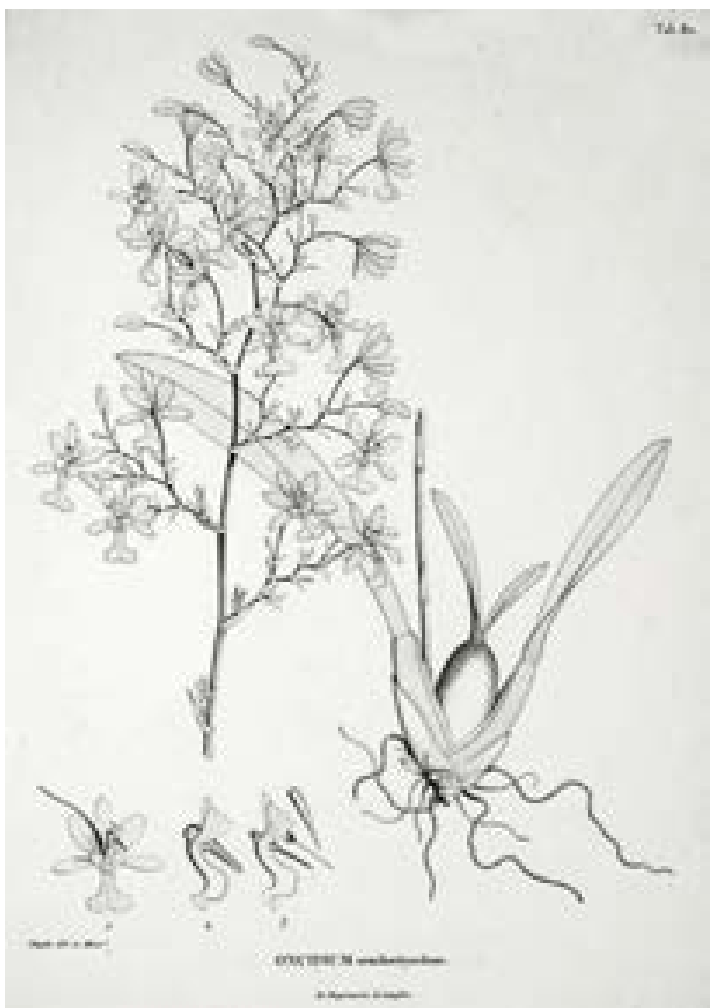

FIgURA 5. Lámina no. 80 que acompaña la publicación original de Oncidium ornithorhynchum en la obra Nova Genera et Species Plantarum, basada en el ejemplar colectado por Humboldt y Bonpland en América y conservado en el herbario de París.

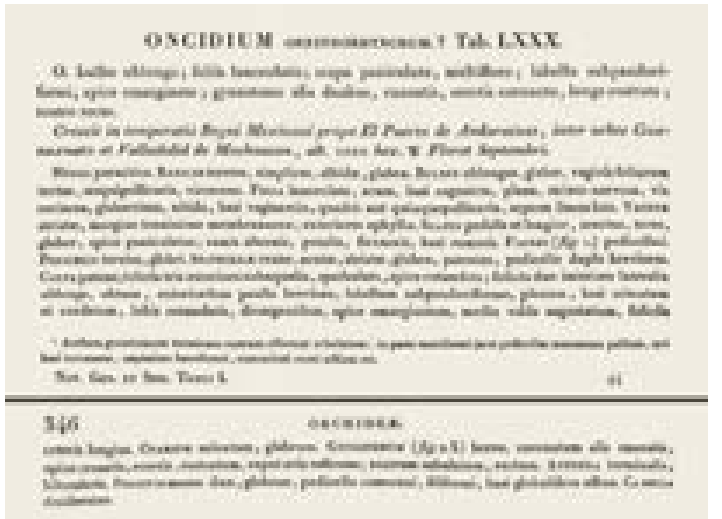

Figura 6. Descripción taxonómica original de Humboldt,

Bonpland \& Kunth, 1815, pp. 345-346.

ornithorhynchum en el norte de Bogotá y la describen como un género con flores $(18 \times 12 \mathrm{~mm})$ y hojas $(30 \times 5 \mathrm{~cm})$, "plantas medianas o pequeñas con o sin seudobulbos. Inflorescencia basal en racimo

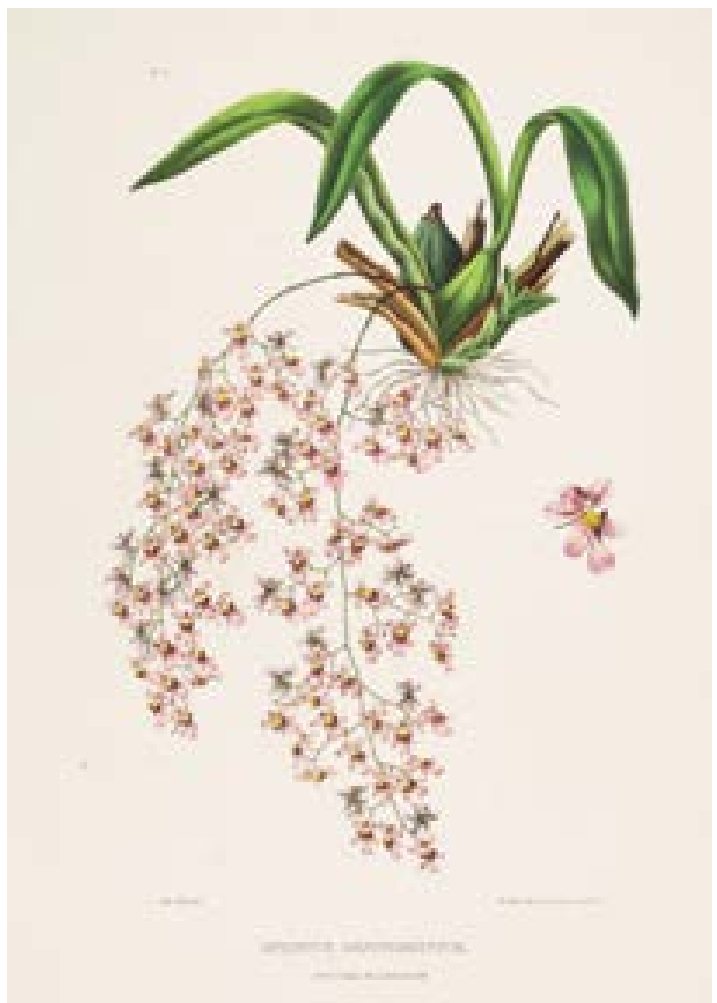

FIgURA 7. Lámina que acompaña la publicación original de Oncidium ornithorhynchum en la obra Orchidaceae of Mexico and Guatemala.

de pocas hasta muchas flores y variados tamaños, muchas veces vistosas. Se encuentra desde México hasta Chile, en todos los climas". Estos autores dan una distribución claramente equivocada, siguiendo lo reportado por Kunth en cuanto a la localidad del tipo de O. ornithorhynchum como: "El Puerto Andaracuas, entre Guanajuato y Valladolid, Michoacán" (Jiménez \& Hágsater 2010). Esa localidad corresponde a la provincia fisiográfica conocida como la Altiplanicie mexicana meridional y El Bajío, una zona muy seca, donde abundan los encinares secos, muy pobres en orquídeas epífitas, siendo la más frecuente Laelia speciosa Kunth (Hágsater et al. 2005).

De acuerdo con el reporte del GBIF (Global Biodiversity Information Facility) habría 131 ocurrencias de Oncidium ornithorhynchum en América incluyendo, de norte a sur, los siguientes países: Estados Unidos (1), México (88), Guatemala (6), Nicaragua (2), El Salvador (3), Panamá (1), 


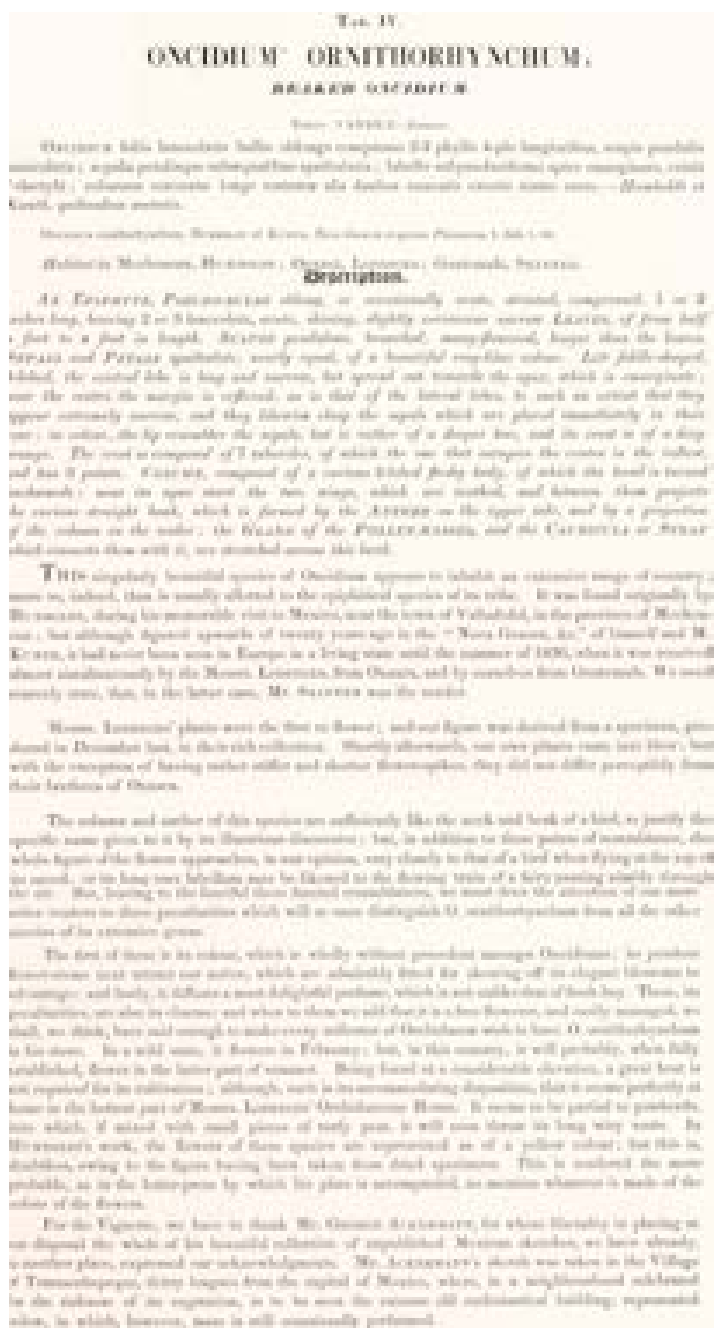

FiguRA 8. Descripción taxonómica original de James

Bateman, 1837, pp. 34-35.

Colombia (27) y Ecuador (3) (GBIF, consultado en noviembre 6 de 2013), sin reportarse hasta la fecha en esta base de datos ocurrencias de esta especie en otros países (Ortiz-Valdivieso S.J 2000). Sin embargo, al revisar el detalle de las plantas centroamericanas incluidas en este reporte, la imagen asociada es una orquídea violeta que, de acuerdo con el reporte de Jiménez y Hágsater (2010), correspondería mejor a Oncidium sotoanum.

Las últimas descripciones científicas de esta orquídea al iniciarse el siglo XXI incluyen las publicaciones enfocadas a la vez al ámbito botánico como al ámbito filogenético. Dentro de estas

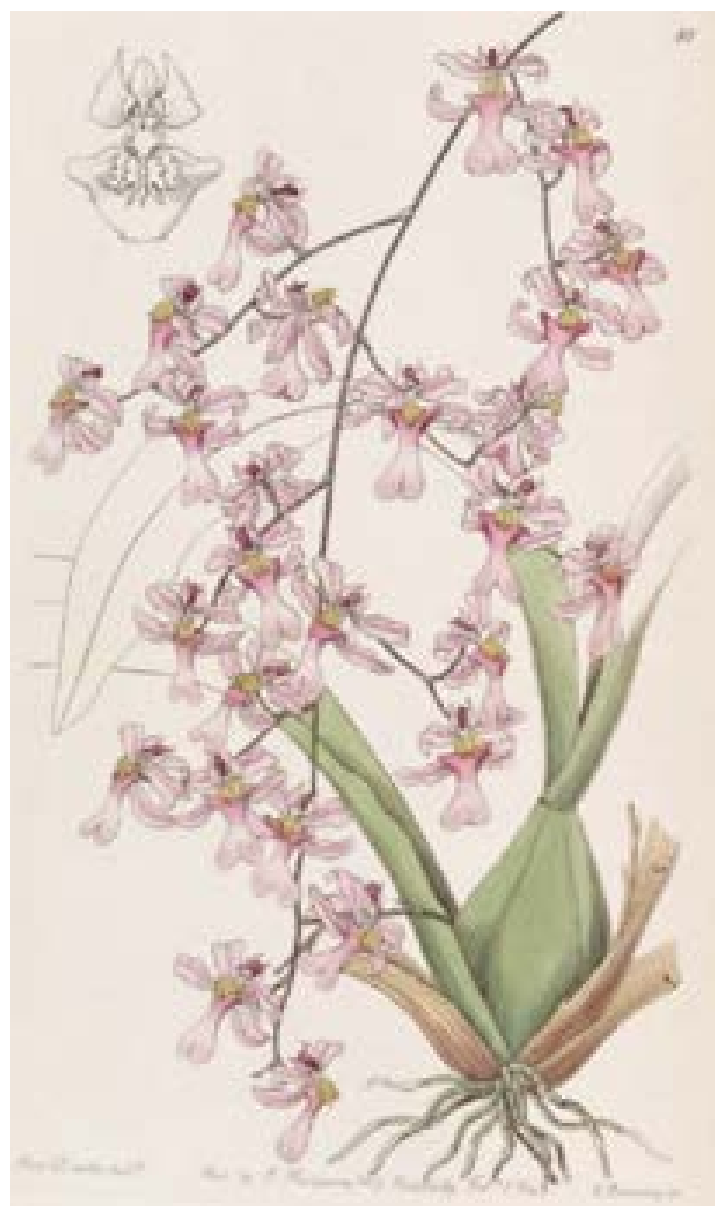

Figura 9. Lámina que acompaña la publicación original realizada por John Lindley en Edwards's Botanical Register.

se encuentran "Comparative histology of floral elaiophores in the orchids Rudolfiella picta (Schltr.) Hoehne (Maxillariinae sensu lato) and Oncidium ornithorhynchum H.B.K (Oncidiinae sensu lato)" realizada por Kevin L. Davies y Malgorzata Stpiczynska en el año 2009. También, el artículo de Rolando Jiménez Machorro y Eric Hágsater del año 2010 que hemos venido citando, titulado "Oncidium ornithorhynchum, una especie mal interpretada y un nombre para una vieja especie: Oncidium sotoanum (Orchidacee)", en el que corrigen definitivamente el nombre de esta planta mexicana. Por otra parte, nuestro grupo publicó en 2012 el artículo "Extraction and amplification of DNA from orchid exsiccates conserved for more than half a century in a herbarium 
ist

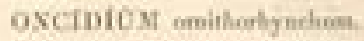

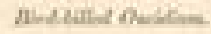

imsonect wownekr.

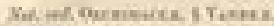

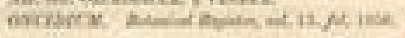

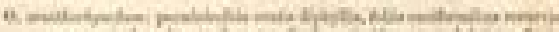

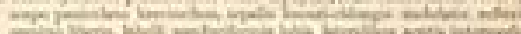

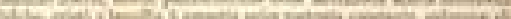

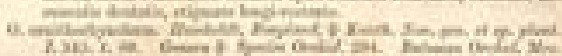

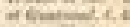

6. rermet inei

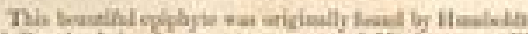

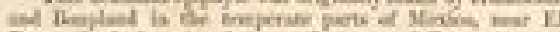

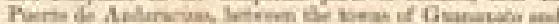

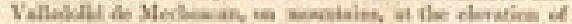

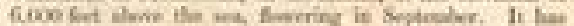

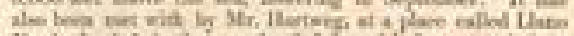

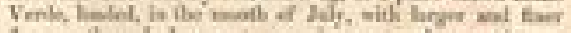

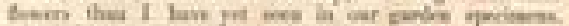

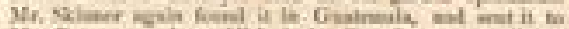

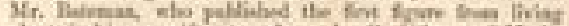

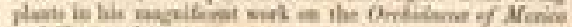

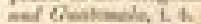

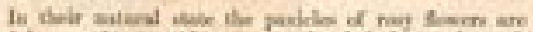

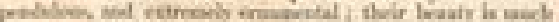

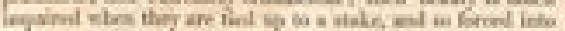

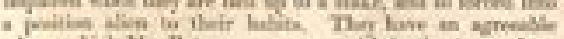

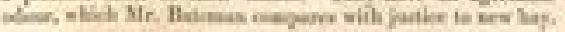

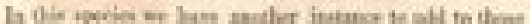

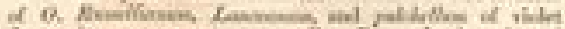

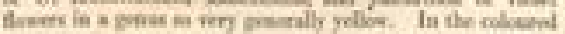

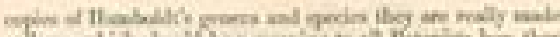

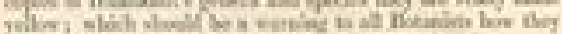

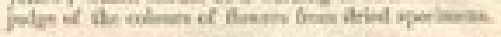

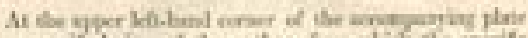

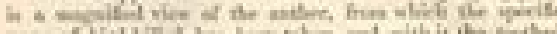

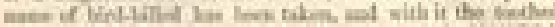

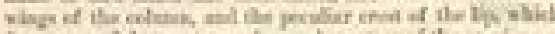

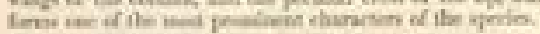

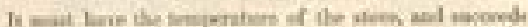

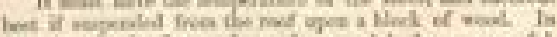

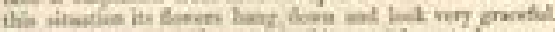

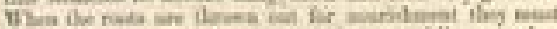

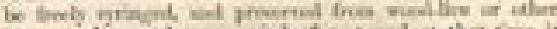

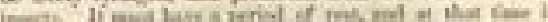

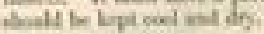

Figura 10. Descripción taxonómica original de John Lindley, 1840, pp. 30-31.

in Bogotá, Colombia", reportando la presencia de Oncidium ornithorhynchum en Duitama (Boyacá) a 2870 metros de altura y también en Santandercito (Cundinamarca) a 2000 metros de altura, de acuerdo con los registros del herbario "Lorenzo Uribe Uribe S. J." de la Pontificia Universidad Javeriana (Mazo et al. 2012).

\section{S54 Prof. Lindiley en new Ordinlaceoss Plast.}

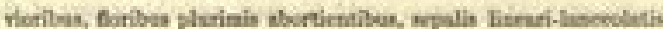

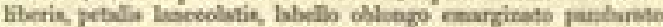

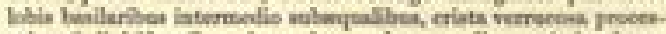

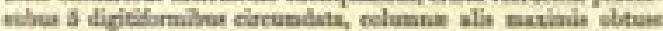
lobatia.

Qvite (Martweg).

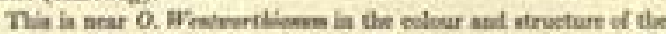

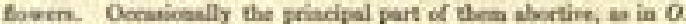

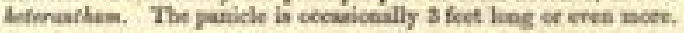

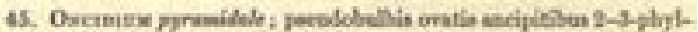

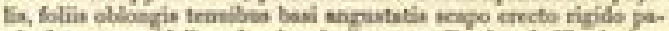

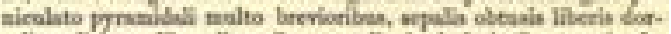

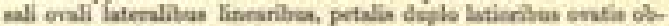

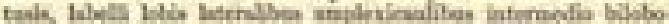

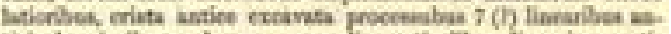

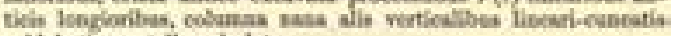
sulobatis, ronteilh sulolsto.

Peate (Hartweg).

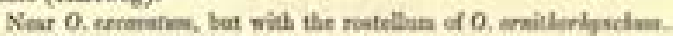
Scape in foct and a half ligh.

FIgURA 11. Descripción taxonómica original de William Jardine et al. 1845 , p. 384.

0. CAryoupgenenis: aff; pyramidali labello basi latiori quam antice, carisulis liscanhus in basi his ternis, notdia posterion apice trifida, alis divergeati biblis. Prewdolnolhi oblongi angusti uncipites mosephylli, folia a hai cuesata liserailizulata (pollicen Iata) acutieseula ( -5 pollices lespa); panicola eleseata (-bipedalis), brachyclada ( -4 pellices, ramerum flexaesorum ramuli abbreviati, fractiflesi, basilares 3-5 fleri, luacteas triangelae acutue ovariite pedicellatis ulsn gaispuies breviorn:

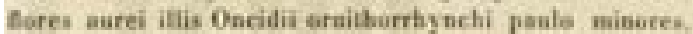
sepalam dersale ovatum cuneatan, sepala lateralia sblonga cuneata aliquid losgiora, Iepola evata nupe basiin nubiso et beevissime cuscate, labellsm a hat lirevissine ac late snguicslata margine lasilari postico et antice reniforine, untice medio angustatum in anzuem laten labi anediani, divercenti hilobulati obtasanguli parti suprabasilari haud aequilate, carinula lineariv sutice tridentata parna is hisi, adjecta utrisque lineola divergens, praepositae lineolan terase carinatar, gynodemium recurratum, asolroclinium valife sebulatum urailherrhynchum, alae lineares, apice Nirieque falcatar, falcula superiori vulgo bidentata, tabula infrastienatica rotundata valde protresa. Neles Oscidium pranidale Linall! Dieves ist fabcesehen vou gelleckter, crusser Diathe) veruchicden dureh grusuere, unten breitere Pursdobolbi, breitere Btinter, eine Lippe, Aeres forund sehmaler, als Vordersuck, deren Hitelstuck viel beeiter st; Jeren Leintensysem einea gas andern Plan zeigt: eine weniger keck ruruchgeborene Siule mit eiafachen linealea Flugela; eine uber dran firuade viel aturher abeesetste Tabula infranigmatiea. Xeu-Giranads; WeatCoedtlleren. - So unbedentend die eisuelsen Bluther sind, so mus die got culsirirte Manze eisen pracblvollen Eindruck machen.

Figura 12. Descripción taxonómica original de Berthold Seemann y Wilhelm Seemann. 1854, p. 108 


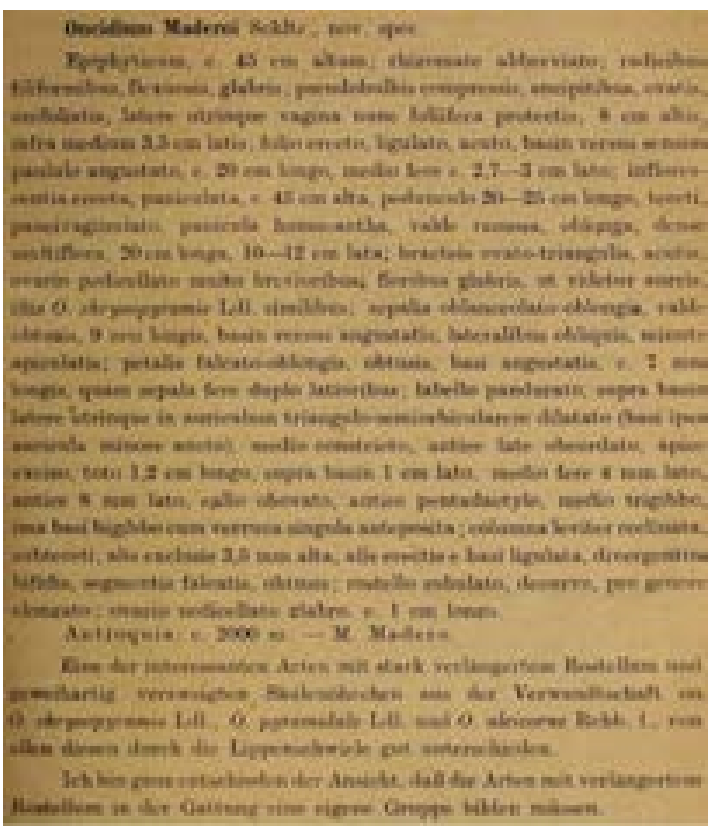

FiguRa 13. Descripción taxonómica original de Friedrich Fedde, 1920, p. 191.

Discusión. Al comparar cada una de estas publicaciones se observan varias inconsistencias en el epíteto específico, en el color de la flor y en el hábitat de la orquídea Oncidium ornithorhynchum (Tabla 1). En cuanto al color de la flor, tanto Lindley como Bateman hacen referencia en sus publicaciones a la obra de Humboldt (Nova Genera et Species Plantarum), el primero citando como colaboradores a Bonpland y a Kunth, como debe ser, y el segundo solamente a Kunth, excluyendo inexplicablemente a Bonpland. Mencionan que hay dos copias de esta obra coloreadas a mano donde las flores de esta especie se representan de color amarillo, afirmando que seguramente se debía a que el dibujo se hizo a partir de un espécimen seco (Jiménez \& Hágsater 2010), sin considerar que el error podría corresponder, alternativamente, a un error de transcripción del lugar de colección de la planta llevada a Europa por Humboldt y Bonpland.

En 1990, Miguel Ángel Soto tuvo la oportunidad de ver en el herbario de París el ejemplar tipo de Oncidium ornithorhynchum (Fig. 4), y allí constató que la especie que se encontraba distribuida en México no correspondía con dicho ejemplar. Posteriormente, en 1997, Adolfo Espejo viajó al herbario de París y tuvo la posibilidad de tomarle una foto al ejemplar tipo

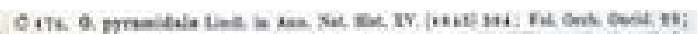

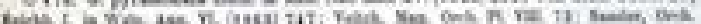

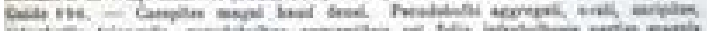

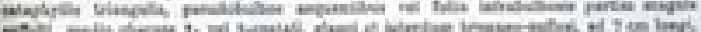

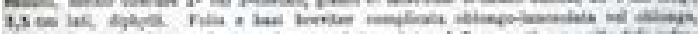

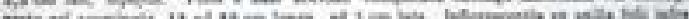

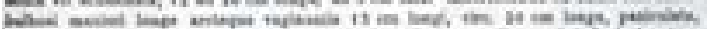

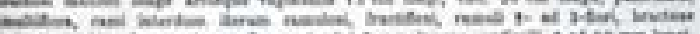

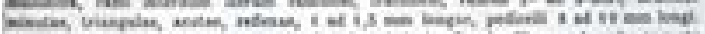

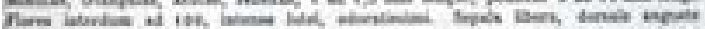

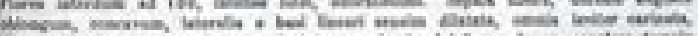

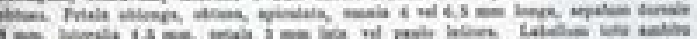

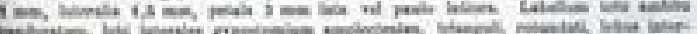

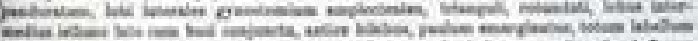

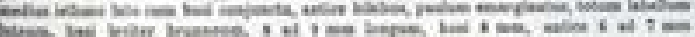

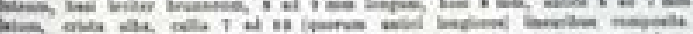

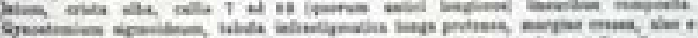

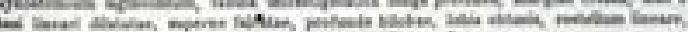

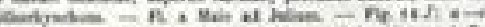

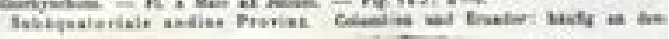
$+x^{n}$

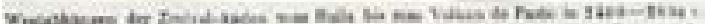

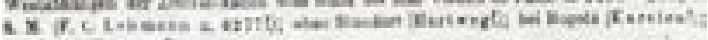
is Quts Rarvies?

FiguRA 14. Descripción taxonómica original de Fritz Krænzlin, 1922, pp. 195-196.

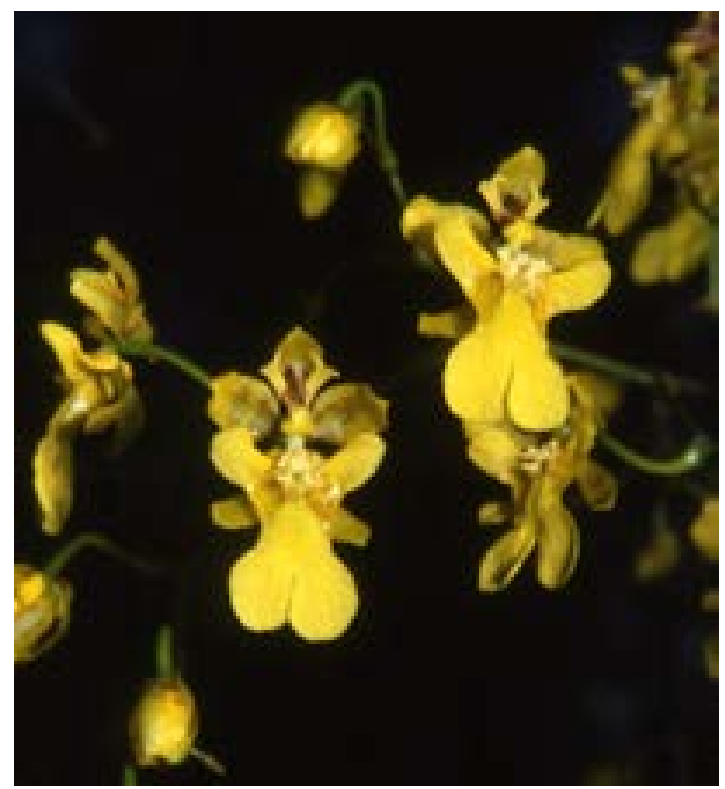

FigURA 15. Foto de Oncidium ornithorhynchum. Tomada por Pedro Ortiz-Valdivieso, S.J. $\uparrow$ Colombia.

de O. ornithorhynchum (Jiménez \& Hágsater 2010). Con la ayuda de esta imagen, al examinar y comparar los ejemplares tipo de Oncidium, Rolando Jiménez confirmó en el año 2008 que la especie encontrada en el herbario de París, no concordaba con la especie que se distribuye en México y Centroamérica, en razón a las marcadas diferencias físicas que hay entre los dos ejemplares (Jiménez \& Hágsater 2010). La especie que se encuentra en el herbario de París, presenta un margen membranoso en las vainas foliosas de la base del pseudobulbo; hay una sola inflorescencia 


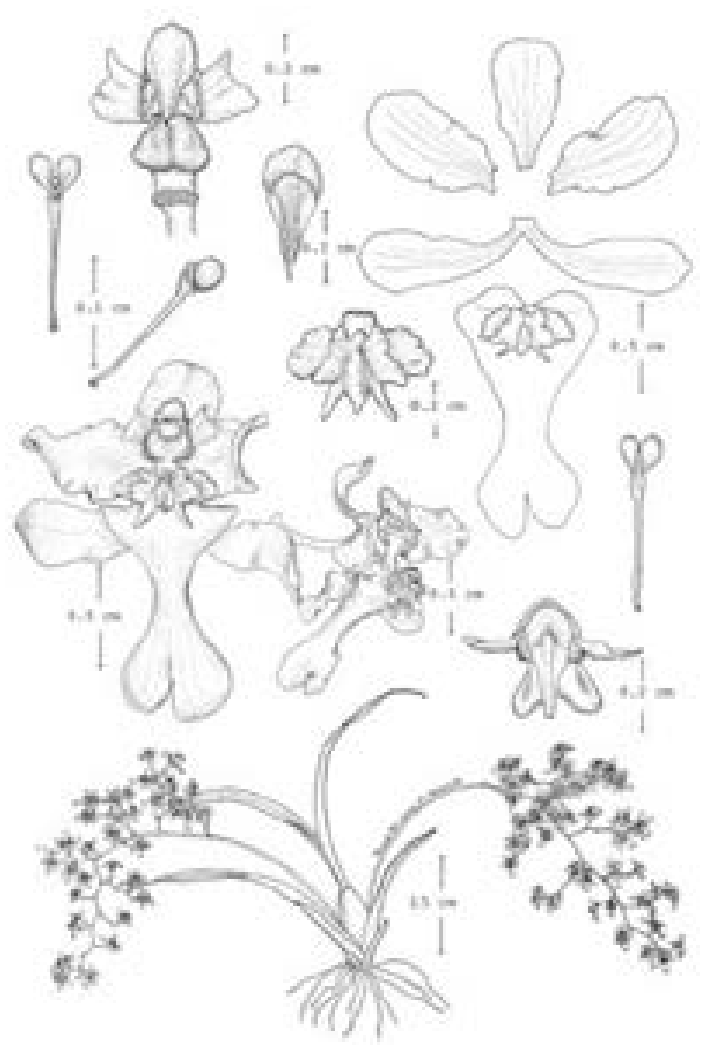

FIgURA 16. Oncidium sotoanum R. Jiménez \& Hágsater. Basado en R. Jiménez 626, Orizaba Veracruz, Mexico, AMO [ilustración tomada de Icon. Orchid. (Mexico)1: pl.77].

por pseudobulbo, erecta, con las ramas de la base alargadas, acortándose gradualmente hacia el ápice (inflorescencia piramidal), el pedúnculo y raquis son casi erectos, ligeramente sinuosos, el callo del labelo se compone de dos quillas cortas hacia los lados y otras tres hacia el ápice, las alas de la columna son erectas y cuneadas. En contraste, la especie mexicana tiene flores violetas con callo amarillo, el margen de las vainas foliosas es membranáceo pero este es inconspicuo, midiendo $1 \mathrm{~mm}$ de ancho; cada pseudobulbo produce simultáneamente 2-4 inflorescencias arqueadocolgantes, con las ramas de la base del raquis cortas, las de la mitad largas y las del ápice cortas; el raquis es en zigzag, el callo es distinto y las alas son oblicuamente dolabriformes y paralelas al cuerpo de la columna (Jiménez \& Hágsater 2010).

Debido a la confusión en la descripción de esta especie, Rolando Jiménez y Eric Hágsater, en su

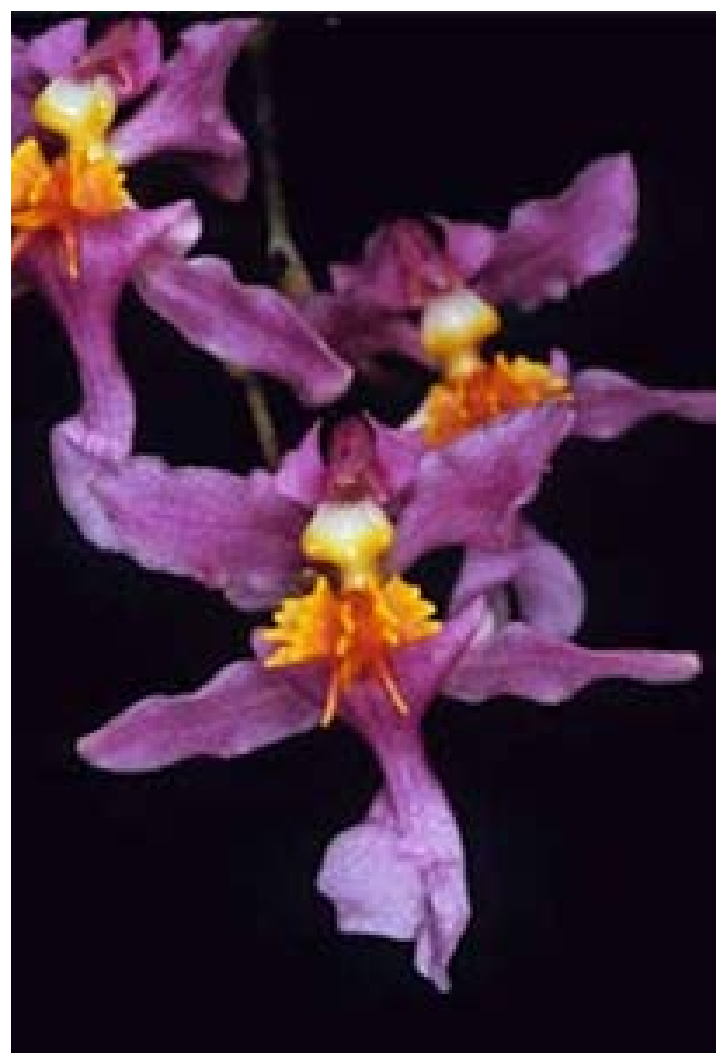

FIgURA 17. Foto de Oncidium sotoanum R. Jiménez \& Hágsater; M. A. Soto 4900, Chiapas. Tomada por de R. Jiménez M.

artículo de 2010, postularon que debe haber un error en la indicación de la localidad del Oncidium ornithorhynchum, colectada por Humboldt y Bonpland, como si fuera de México. El ejemplar tipo, que se conserva en París, tanto como el dibujo correspondiente, muestran que este espécimen no es lo que a partir de Lindley se ha considerado como "Oncidium ornithorhynchum de México y Centroamérica" (y no de Suramérica), sino que corresponde a lo que se ha llamado Oncidium pyramidale de Colombia, Ecuador y Perú, siendo este $O$. pyramidale sinónimo de O. ornithorhynchum (Fig. 15). Por otra parte, la especie mexicana con flores violetas, se conoce ahora, con razones bien fundamentadas, como Oncidium sotoanum (Fig. 16-17). A pesar que se ha propuesto a Oncidium chrysopyramis Rchb.f. como sinónimo de O. ornothorhynchum, Rolando Jiménez y Eric Hágsater establecen que al presentar esta especie una 


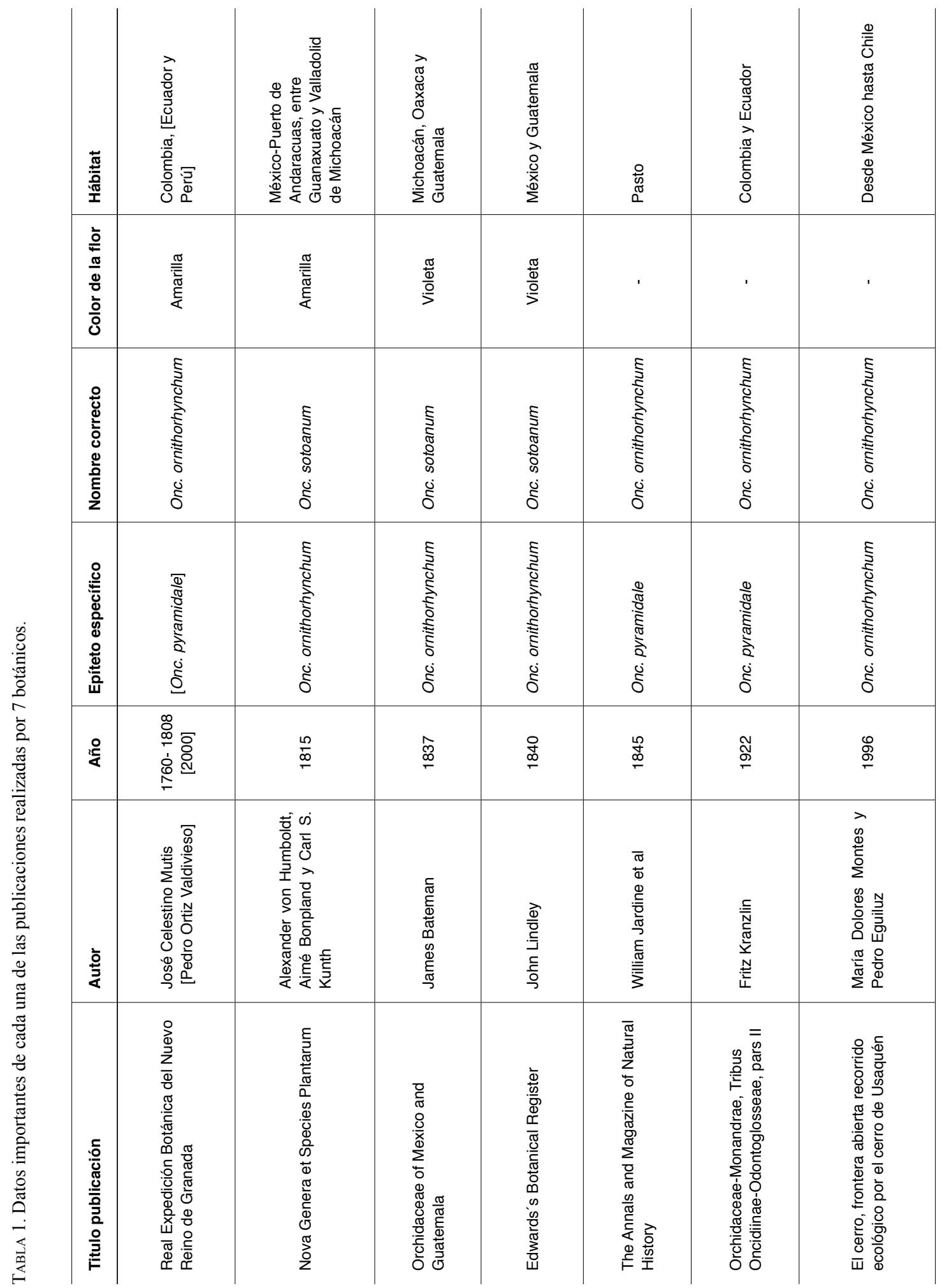


TABLA 2. Resumen de las publicaciones mencionadas a lo largo del escrito.

\begin{tabular}{|c|c|}
\hline Año & Autor \\
\hline $1760-1808$ & $\begin{array}{l}\text { José Celestino Mutis, quien colecta en el Nuevo Reino de Granada a partir de } 1760 \text { y fallece en } 1808 \text {, dirige } \\
\text { la Real Expedición Botánica del Nuevo Reino de Granada y describe Oncidium ornithorhynchum denominada } \\
\text { posteriormente como Oncidium pyramidale en la Flora de la Real Expedición Botánica del Nuevo Reino de } \\
\text { Granada (Real Expedición Botánica del Nuevo Reino de Granada, 1783-1816). }\end{array}$ \\
\hline 1801 & $\begin{array}{l}\text { Alexander von Humboldt y Aimé Bonpland viajan a Sudamérica y colectan la orquídea que bautizan Oncidium } \\
\text { ornithorhynchum. La depositan en el herbario de París. (Jiménez \& Hágsater 2010). }\end{array}$ \\
\hline 1815 & $\begin{array}{l}\text { Carl S. Kunth, con base en el tipo colectado por Humboldt y Bonpland, publica la especie Oncidium } \\
\text { ornithorhynchum en su obra Nova Genera et Species Plantarum (Humboldt, Bonpland \& Kunth 1815). }\end{array}$ \\
\hline 1836 & $\begin{array}{l}\text { Theodor Hartweg le envía a Loddiges una orquídea con el nombre Oncidium ornithorhynchum colectada en } \\
\text { Oaxaca, México, de tal forma que la introdujo al cultivo en Europa; también este año George Skinner le envía una } \\
\text { James Bateman. Flores violetas. (Jiménez \& Hágsater 2010). }\end{array}$ \\
\hline 1837 & $\begin{array}{l}\text { James Bateman publica una orquídea con el nombre Oncidium ornithorhynchum en su obra Orchidaceae of } \\
\text { México and Guatemala. Flores violetas (Bateman 1837). }\end{array}$ \\
\hline 1840 & $\begin{array}{l}\text { John Lindley publica esta orquídea en Edwards's Botanical Register con el nombre de Oncidium } \\
\text { ornithorhynchum (Lindley 1840). }\end{array}$ \\
\hline 1845 & $\begin{array}{l}\text { William Jardine et al. la publican como Oncidium pyramidale en The Annals and Magazine of Natural } \\
\text { History (Jardine et al. 1845). }\end{array}$ \\
\hline 1854 & $\begin{array}{l}\text { Berthold Seemann y Wilhelm Seemann reportan Oncidium chrysopyramis Rchb. f \& Warsz como sinónimo } \\
\text { de Oncidium pyramidale en Bonplandia 2: } 108 \text { (Seemann \& Seemann 1854). }\end{array}$ \\
\hline 1920 & $\begin{array}{l}\text { Fedde publica Oncidium maderoi como sinónimo de Oncidium pyramidale en Repertorium Specierum } \\
\text { Novarum Regni Vegetabilis (Fedde 1920). }\end{array}$ \\
\hline 1922 & $\begin{array}{l}\text { Fritz Kranzlin publica esta especie como Oncidium pyramidale en la obra Orchidaceae-Monandrae, Tribus } \\
\text { Oncidiinae-Odontoglosseae pars // (Kranzlin 1922). }\end{array}$ \\
\hline 1968 & $\begin{array}{l}\text { Pedro Ortiz Valdivieso, S.J., reporta Oncidium ornithorhynchum en Colombia, y en el año } 1975 \text { la deposita } \\
\text { en el herbario de la Pontificia Universidad Javeriana. Esta concuerda con la planta denominada Oncidium } \\
\text { pyramidale de la Real Expedición Botánica y con la planta denominada Oncidium ornithorhynchum de la } \\
\text { colección de Humboldt y Bonpland depositada en el Herbario de París }\end{array}$ \\
\hline 1990 & $\begin{array}{l}\text { Miguel Ángel Soto viaja a París y ve que la Oncidium ornithorhynchum que está en el herbario no } \\
\text { concuerda con orquídeas mexicanas de la misma región (Jiménez \& Hágsater 2010). }\end{array}$ \\
\hline 1996 & $\begin{array}{l}\text { María Dolores Montes y Pedro Eguiluz publican una Oncidium ornithorhynchum en su libro El cerro, } \\
\text { frontera abierta recorrido ecológico por el cerro de Usaquén especificando que esta especie de encuentra } \\
\text { desde México hasta Chile (Montes \& Eguiluz 1996). }\end{array}$ \\
\hline 1997 & $\begin{array}{l}\text { Adolfo Espejo viaja al herbario de París y le toma una foto al tipo de Oncidium ornithorhynchum (Jiménez } \\
\text { \& Hágsater 2010). }\end{array}$ \\
\hline 2008 & $\begin{array}{l}\text { Rolando Jiménez, con base en la foto tomada por Adolfo Espejo, compara O. ornithorhynchum de París } \\
\text { con la especie de México (Jiménez \& Hágsater 2010). }\end{array}$ \\
\hline 2010 & $\begin{array}{l}\text { Rolando Jiménez y Eric Hágsater, publican que el tipo de Oncidium ornithorhynchum conservado en París } \\
\text { coincide con la Oncidium pyramidale que se distribuye en Colombia, Ecuador y Perú de tal forma que el } \\
\text { nombre Oncidium pyramidale queda como sinónimo del primero. En cuanto a la Oncidium ornithorhynchum } \\
\text { que se distribuye en México, fue renombrada con el nombre de Oncidium sotoanum (Jiménez \& Hágsater } \\
\text { 2010). }\end{array}$ \\
\hline 2011 & $\begin{array}{l}\text { Laura Mazo et al. establecen la secuencia de los genes matK de tres (3) especímenes de Oncidium } \\
\text { ornithorhynchum colectados en Colombia (Madrid-Cundinamarca y Duitama-Boyacá) de los cuales el } \\
\text { primero correspondía a una planta fresca y los dos restantes se encontraron conservados en el "Herbario } \\
\text { Julián Uribe Uribe S. J." de la Pontificia Universidad Javeriana, con } 36 \text { y } 43 \text { años de antigüedad, } \\
\text { respectivamente (Mazo et al. 2012). }\end{array}$ \\
\hline
\end{tabular}


inflorescencia más laxa, no en forma "piramidal", flores de menor tamaño y alas más angostas, es definitivamente diferente a la morfología de Oncidium pyramidale (Jiménez \& Hágsater 2010).

En conclusión, tanto John Lindley como James Bateman, ilustraron una especie con flores rosadas o violetas, hábitat en México y con el nombre erróneo de Oncidium ornithorhynchum, diferenciándose un poco de Kunth quien la publicó con este mismo nombre y hábitat, aunque, a diferencia de los dos botánicos anteriores, la describió de manera explícita como una orquídea con flores amarillas. En contraste, tanto José Celestino Mutis, como Fritz Kranzlin y William Jardine la clasificaron con el nombre de Oncidium pyramidale, flores amarillas (únicamente en la descripción de Mutis) y como hábitat: Colombia, Perú y Ecuador. Es importante recalcar que estos últimos 3 botánicos concuerdan con Kunth en el color amarillo de la flor, y se diferencian principalmente en su localización biogeográfica.

Lo anterior se explica gracias a la aclaración realizada por Jiménez y Hágsater, en donde se deduce que las descripciones de John Lindley y James Bateman corresponden ciertamente con la orquídea presente en México pero se equivocaron al nombrarla (siguiendo a Kunth) como Oncidium ornithorhynchum. Jiménez y Hágsater aclaran así, finalmente, la identidad de la planta centroamericana, distribuida en el sur de México y Centroamérica, como una nueva especie llamada Oncidium sotoanum y, a su vez, describen una nueva subespecie $O$. sotoanum ssp. papalosmum Jiménez, conocida únicamente de los estados de Oaxaca y Chiapas, México.

En el presente artículo nosotros postulamos que:

1. La orquídea descrita en Bogotá antes de 1808 por José Celestino Mutis, y luego en el curso del siglo XIX por Fritz Kranzlin y por William Jardine, con flores amarillas, distribución en Colombia, Perú, Ecuador, y denominada Oncidium pyramidale, es la que correspondería al mismo ejemplar publicado por Kunth con el nombre de Oncidium ornithorhynchum, en consonancia con que el epíteto especifico Oncidium pyramidale haya pasado a ser sinónimo del primero.

2. El ejemplar tipo de Oncidium ornithorhynchum que se encuentra hoy en el Herbario Histórico del
Musée National d'Histoire Naturelle de Paris, y que tuvimos la ocasión de volver a examinar en el mes de marzo del presente año, correspondería mejor a una orquídea colectada en el territorio que se llamaba en aquella época "Virreinato de la Nueva Granada", y que comprende hoy territorios de Colombia y Ecuador.

3. El registro manuscrito de esta orquídea en el Diario botánico o "Journal botanique" de Aimé Bonpland, podrá aclarar el origen biogeográfico del ejemplar tipo conservado en París, puesto que en general cada uno de los registros de este libro de campo fueron inscritos en orden consecutivo y cronológico, y podemos deducir, con base en las consideraciones del presente artículo, que el registro de esta especie se hallará en el tramo correspondiente a la zona sur de la actual Colombia, o bien a la zona Norte del actual Ecuador con fechas entre septiembre de 1801 y mayo de 1802 .

4. Finalmente, nos proponemos intentar la comparación molecular del exsicado tipo conservado en París con ADN extraído de ejemplares de Oncidium ornithorhynchum colectados en Colombia o Ecuador.

Agradecimientos. Los autores agradecen al personal del Herbario "Lorenzo Uribe, S.J." (Facultad de Ciencias, Pontificia Universidad Javeriana), a los miembros del Instituto de Genética Humana (Facultad de Medicina, Pontificia Universidad Javeriana), particularmente a los colegas del grupo de investigación en ADN antiguo, así como a las doctoras Marpha Telepova, Cécile Aupic y Myriam Gaudeul, del Musée National d'Histoire Naturelle de Paris, y a la museógrafa Claudia Navas-Courbon, en la misma ciudad. Dedicamos este artículo a la memoria del Padre Pedro Ortiz Valdivieso, S.J. $\dagger$

\section{LiTERATURA CITADA}

Asociación Bogotana de Orquideología. http://www. orquideasbogotaabo.com/index.php?option $=\mathrm{com}$ content $\&$ view $=$ article $\& i d=72 \&$ Itemid $=30$. Consultado: 17-01-2013.

Bateman, J. 1837-1843. Oncidium ornithorhynchum. Pp 34-35 in: The Orchidaceae of Mexico and Guatemala. London, Ridgway.

Davies, K. L \& M. Stpiczynska. 2009. Comparative histology of floral elaiophores in the orchids Rudolfiella picta (Schltr.) Hoehne (Maxillariinae sensu lato) and 
Oncidium ornithorhynchum H.B.K. (Oncidiinae sensu lato). Ann. Bot. 104: 221-234.

Díaz-Piedrahita, S. \& C. Vélez-Nauer. 1997. Revisión de las tribus Barnadesiae y Mutisieae (Asteraceae) para la Flora de Colombia. In: Monografías del Jardín Botánico José Celestino Mutis, Vol. 1. Bogotá: Jardín Botánico "José Celestino Mutis".

Fedde, F. 1920. Oncidium maderoi Schltr. In: Repertorium specierum novarum regni vegetabilis. Dahlem bei Berlin: Verlag des repertoriums, Fabeckstr. 191 p.

Global Biodiversity Information Facility (GBIF) http:// data.gbif.org/occurrences/searchCountries.htm?c[0]. $\mathrm{s}=20 \& \mathrm{c}[0] . \mathrm{p}=0 \& \mathrm{c}[0] . \mathrm{o}=5322086 \quad$ (consultado en: noviembre 6 de 2013)

Hágsater, E., M.A. Soto Arenas, G.A. Salazar Chávez, R. Jiménez Machorro, M.A. López Rosas \& R.L. Dressler. 2005. Las Orquídeas de México. Instituto Chinoín, México, $304 \mathrm{p}$.

Hernández, G., 1968. Archivo epistolar del sabio naturalista José Celestino Mutis. Instituto Colombiano de Cultura Hispanica. Editorial Kelly. Bogotá, D.C. Vol 3, Tomo 1, pp. 277-292.

Humboldt, A., A. Bonpland \& C. S. Kunth. 1815. "Oncidium ornithorhynchum". In: Nova Genera et Species Plantarum. París: Schoell. 1: 345-346.

Jardine, W., P. J. Selby, G. Johnson, C. Babington, J.H. Balfour \& R. Taylor. 1845. Oncidium pyramidale. In: The Annals and Magazine of Natural History, including Zoology, Botany and Geology, Londres: R. and J. E. Taylor. 15: 384.

Jiménez, R. \& E. Hágsater. 2010. Oncidium ornithorhynchum, una especie mal interpretada y un nombre para una vieja especie: Oncidium sotoanum (Orchidaceae). Lankesteriana 9(3): 411- 422.

Kranzlin, F. 1922. Oncidium pyramidale Lindl. Pp. 195196 in: Orchidaceae-Monandrae: Tribus OncidiinaeOdontoglosseae pars II.
Lindley, J. 1840. Oncidium ornithorhynchum. Pp. 30-31 in: Edward's Botanical Register, Vol. III. Londres: James Ridgway and Sonos, Piccadilly.

Mazo, L., A. Gómez, S. Quintanilla, J. Bernal \& P. OrtizValdivieso S.J. 2012. Extraction and amplification of DNA from orchid exsiccates conserved for more than half a century in a herbarium in Bogotá, Colombia. Lankesteriana 12(2): 121-129.

Montes, M.D. \& P. Eguiluz. 1996. El cerro, frontera abierta. Recorrido ecológico por el cerro de Usaquén. Bogotá: Santillana. $110 \mathrm{p}$.

Ortiz-Valdivieso S.J, P. 2000. Oncidium pyramidale Lindl. In: Flora de la Real Expedición Botánica del Nuevo Reino de Granada (1783 - 1816). Vol. XI, Orchideaceae, Vol XI. Tomo 5. Madrid, España. Ediciones de Cultura Hispánica. 51 p.

Ortiz-Valdivieso, P. \& A. Gómez. En imprenta. Las orquídeas de Colombia en la obra de Humboldt, Bonpland y Kunth. In: Los hermanos Alexander y Wilhelm von Humboldt en Colombia. Huellas históricas de la cooperación científica entre dos continentes.

Pridgeon, A. M., P. J. Cribb \& M. W. Chase. 2009. Genera Orchidacearum, Vol. 5. Oxford University Press, Oxford New York.

Proyecto de digitalización de los dibujos de la Real Expedición Botánica del Nuevo Reino de Granada (1783-1816), dirigida por José Celestino Mutis: www. rjb.csic.es/icones/mutis. Real Jardín BotánicoCSIC. Consultado: 14-03-2013

Seemann, B. \& W. Seemann. 1854. Oncidium chrypsopyramis. In: Bonplandia. Vol II. Londres: Williams y Norgate. París: Fr. Klincksieck. 158 p.

Vargas, O.M. 2011. A nomenclator of Diplostephium (Asteraceae: Astereae): a list of species with their synonyms and distributions by country. Lundellia 14 : $32-51$. 
